\title{
ON CHANGES IN CONCEPT AND GENERAL COMPOSITION OF AGRICULTURAL TRACTORS
}

Georgij Tajanowskija, Wojciech Tanaś ${ }^{b^{*}}$, Mariusz Szymanek ${ }^{\mathrm{c}}$

a Belarussian National Technical University, Minsk, Republic of Belarus, tge52@mail.ru ORCID ---

b Department of Agricultural, Forest and Transport Machinery, University of Life Sciences in Lublin, Poland, wojciech.tanas@up.lublin.pl ORCID 0000-0002-9544-8902

c Department of Agricultural, Forest and Transport Machinery, University of Life Sciences in Lublin, Poland, Mariusz.Szymanek@up.lublin.pl 0000-0002-3337-0337

*Corresponding author: e-mail: wojciech.tanas@up.lublin.pl

\begin{tabular}{ll}
\hline ARTICLE INFO & ABSTRACT \\
\cline { 1 - 1 } $\begin{array}{l}\text { Article history: } \\
\text { Received: May } 2019\end{array}$ & $\begin{array}{l}\text { Conclusions on the analysis of the state of development in the tractor } \\
\text { industry are formulated, aspects of the forecasting concept of transfor- } \\
\text { Received in the revised form: } \\
\begin{array}{l}\text { June } 2019 \\
\text { Accepted: June } 2019\end{array}\end{array} \quad \begin{array}{l}\text { mation, general layout solutions and the theory of promising tractor } \\
\text { units with new propulsion systems are considered, a general approach } \\
\text { to the pre-design substantiation of new generation tractors is presented. }\end{array}$ \\
$\begin{array}{l}\text { Key words: } \\
\text { tractor, }\end{array}$ & \\
$\begin{array}{l}\text { construction structure, } \\
\text { drive systems, } \\
\text { equipment modules, } \\
\text { development concept }\end{array}$ &
\end{tabular}

\section{Введение}

Обширная библиография научных работ последних лет на тему электропривода на тракторе отражает научно-практический интерес к рассмотрению вопросов, связанных с изменениями, которые электропривод привносит в структурное построение, компоновочные решения, дизайнерский облик, и того, как влияют варианты двигательной установки на свойства будущего машинного тракторного агрегата (MTA). Такая информация необходима еще на стадии принятия технического задания на проектирование машины. Содержание статьи посвящено рассмотрению отдельных аспектов этой научно-технической задачи.

\section{Актуальные задачи современного тракторостроения}

Анализ публикационной активности авторов в области прогнозов перспектив развития, расчетно-теоретических обоснований, динамики патентования и осуществленных инновационных технических решений сельскохозяйственных тягово-энергетических транспортно-технологических наземных мобильных машин (тракторов, мобильных энергетических средств, универсальных энергетических 
Georgij Tajanowskij, Wojciech Tanaś, Mariusz Szymanek

средств, шасси комбайнов под различные технологии и т.п.) за последний 15 -летний ретроспективный период позволяет отметить ряд особенностей. Среди них:

- повышенное общее внимание к вопросам разработки альтернативных двигательных установок для мобильных машин, как следствие: глобальных проблем с экологией, выбросом парниковых газов; близкого по времени (по разным оценкам - 30-50 лет) исчерпания ископаемых природных жидких углеводородов (при изменении потребления в них по прогрессивной кривой); низкого, не более 0,42-0,48, общего КПД; высоких удельных затрат топлива на единицу полезной мощности ДВС и практически почти достигнутого предела их совершенствования, несмотря на существенное развитие мехатронных автоматических систем управления процессом двигателя и других достижений в их системах топливоподачи, впуска, выпуска, охлаждения и т.п.;

- интенсивное развитие: автоматизированных и автоматических адаптивных трансмиссий, позволяющих обеспечить переключение передач без разрыва потока мощности, на основе планетарно-вальных передач с фрикционными муфтами, в основном «мокрыми» гидропожимными бустерного типа; многопоточных гидродинамических передач, либо на основе бесступенчатых во всем скоростном диапазоне гидростатических полнопоточных объемных гидропередач (ОГП); двухи многопоточных объемных гидромеханических передач (ОГМП) с дифференциальными механическими звеньями; передач на основе электромеханических передач, состоящих из модуля: мотор-генератор плюс тяговый асинхронный электродвигатель со скалярным или векторным управлением в составе гибридной двигательной установки с ДВС, либо на основе чисто электрических передач с асинхронными электромашинами с питанием от электронакопителей аккумуляторного, конденсаторного типа: передач на основе так называемых электрических топливных водородных элементов;

- недостаточное количество комплексных расчетно-теоретических и опытноэкспериментальных обоснований технико-экономической и социальноэкономической эффективности перечисленных до этого инновационных предложений в комплексе и системе с вероятным взаимообусловленным изменением с.-х. технологий, с учетом специфики жизненных циклов новых машин, проблем развития инфраструктуры эксплуатации, ремонта, технологического обеспечения, обучения персонала и, что чрезвычайно важно, безопасности и совокупных затрат созданных человеком финансовых, энергетических, материальных и созданных природой мировых ресурсов, а также экологических потерь в «глобальном переходе развития» от материализации того, что по отдельности представляется выгодным и перспективным;

- формулирование высказываний о необходимости развития общей теории сельскохозяйственного машинного транспортно-технологического мобильного электроприводного агрегата с управлением на основе мехатроники, в том числе роботизированного, и с производством электропитания исключительно от экологически чистых возобновляемых природных источников.

Цель данной работы - попытка представить вероятное изменение концепции, развитие типологии и системных структурных особенностей общих компоновок 
On changes in concept...

перспективных сельскохозяйственных машинных тракторных агрегатов на основе тракторов с альтернативными двигательными установками.

\section{Видовое разнообразие двигательных установок для тракторной техники}

Конструктивное исполнение двигательных установок наземных тяговых машин достаточно разнообразное (Ksenevich, Goberman and Goberman, 2003; Katsygin, 1964). Приведем вариант классификации двигательных установок (ДУ), необходимый в контексте рассматриваемых в работе вопросов.

Представленная выборочная таблица сформирована с учетом потенциальных достоинств и преимуществ включенных в таблицу ДУ, приспособленности к созданию на их основе квази- и полностью бесступенчатых моторно-трасмиссионнодвижительных установок (МТДУ), обеспечивающих максимально возможные общие КПД во всем скоростном диапазоне с благоприятными тягово-динамическими характеристиками, в том числе на переходных режимах, а также защиту элементов МТДУ от пиковых динамических нагрузок в практически опасных, с точки зрения надежности, участках частотного спектра нагружения. Однако сроки появления перечисленных в таблице, избавленных от присущих им недостатков и доведенных до нужных эксплуатационных показателей образцов ранее не распространенных перспективных ДУ, зависят слишком от многих факторов.

Таблица 1.

Выборка из классификации перспективных двигательных установок для применения на современных сельскохозяйственных тракторных агрегатах

\begin{tabular}{|c|c|c|}
\hline А - признак & Б- признак & B - признак \\
\hline \multirow{7}{*}{ Тепловые ДУ } & Дизельные ДВС & $\begin{array}{l}\text { На синтетическом топливе } \\
\text { растительного происхождения }\end{array}$ \\
\hline & $\begin{array}{l}\text { Газовые двигатели } \\
\text { внутреннего сгорания }\end{array}$ & На баллонном природном газе \\
\hline & & $\begin{array}{l}\text { На водороде высокого } \\
\text { давления }\end{array}$ \\
\hline & Внешнего сгорания & $\begin{array}{l}\text { Двигатель Стирлинга альфа- } \\
\text { типа }\end{array}$ \\
\hline & & $\begin{array}{l}\text { Двигатель Стирлинга бетта- } \\
\text { типа }\end{array}$ \\
\hline & & Газодизельный цикл с циклом \\
\hline & Комбинированные & $\begin{array}{l}\text { Стирлинга для отработавших } \\
\text { газов в 6-ти тактном двигателе }\end{array}$ \\
\hline \multirow{5}{*}{ Гибридные ДУ } & & Последовательной схемы \\
\hline & Дизель-генераторные с & Параллельно- \\
\hline & асинхронными & последовательной схемы \\
\hline & электромашинами & $\begin{array}{l}\text { Многопоточные с } \\
\text { электромотор-колесами }\end{array}$ \\
\hline & $\begin{array}{l}\text { Дизель-генераторные с } \\
\text { вентильным индукторным } \\
\text { тяговым электродвигателем }\end{array}$ & С независимым возбуждением \\
\hline
\end{tabular}


Georgij Tajanowskij, Wojciech Tanaś, Mariusz Szymanek

\begin{tabular}{|c|c|c|}
\hline $\begin{array}{l}\text { СПДГ - свободнопоршневой } \\
\text { линейный двигатель } \\
\text { внутреннего сгорания с } \\
\text { линейным электрическим }\end{array}$ & $\begin{array}{l}\text { Двухцилиндровые } \\
\text { динамически уравновешенные }\end{array}$ & С отбойниками \\
\hline $\begin{array}{l}\text { Электронакопитель + тяговый } \\
\text { асинхронный }\end{array}$ & $\begin{array}{l}\text { Электрохимический } \\
\text { накопитель }\end{array}$ & $\begin{array}{l}\text { Литий-ионные } \\
\text { аккумуляторные батареи } \\
\text { Литий-железо-фосфатные } \\
\text { батареи }\end{array}$ \\
\hline электродвигатель & $\begin{array}{l}\text { Емкостной накопитель } \\
\text { энергии }\end{array}$ & $\begin{array}{l}\text { Суперконденсаторы на } \\
\text { графеновой основе } \\
\text { Ионисторы }\end{array}$ \\
\hline $\begin{array}{l}\text { Емкость водорода }+ \\
\text { Водородные топливные } \\
\text { элементы +тяговый } \\
\text { электродвигатель }\end{array}$ & $\begin{array}{l}\text { Тип: АFC (либо: PEMFC, } \\
\text { PAFC, MCFC, SOFC) }\end{array}$ & $\begin{array}{l}\text { С заправочными модулями } \\
\text { «твердого» водорода }\end{array}$ \\
\hline
\end{tabular}

\section{О выборе вариантов перспективных сельскохозяйственных тракторных агрегатов}

Изменение типа двигательной установки неизбежно приводит к структурным изменениям компонентного элементного состава, несущих систем, общих компоновочных схем, дизайнерских решений экстерьера машинного тракторного агрегата и, как следствие, набора и показателей их функциональных свойств, что в определенные моменты переходит в новое качество - изменение концепции МТА. Так произошло с изменением тяговой концепции трактора на тягово-энергетическую и, вероятно далее, на условно называемую в данной статье - мобильно-энергетическую. В работах проф. Ксеневича И.П. еще в 80-х годах прошлого столетия сформулированы выводы о вероятных направлениях развития МТА (Ksenevich, Goberman and Goberman 2003; Ksenevich, Gus'kov and Bocharov 1991; Ksenevich, Skotnikov and Lyasko 1985). Теперь как раз пришло время осуществления в основных чертах тех прогнозов и их корректировки с учетом реализованных на практике разработок новых технических решений ДУ, трансмиссий, движителей, систем агрегатирования и отбора мощности тракторных средств, развития с.-х. технологий и наборов сельхозмашин для их осуществления. Появление разработок (в ближайшее время в 5-10 лет) перечисленных компонент тракторных средств стало возможным, в том числе, и на основе выполненных в те годы в тесном сотрудничестве с тракторостроительными заводами разработок научных школ белорусских ученых: д.т.н., профессоров Кацыгина В.В., Цитовича И.С., Скотникова В.А., Тарасика В.П, Гуськова В.В. и др.

С интенсивным развитием принципов блочно-модульного построения и многооперационности МТА, комплекса средств агрегатирования и многочисленных систем отбора мощности к развитому набору активных рабочих органов (АРО) и разветвленному приводу колес на агрегатируемых с центральным энергомодулем, разнообразных по назначению прицепных звеньев, теория трактора, с учетом всего отмеченного, становится элементом более общей теории МТА. Так как отдельное звено МТА не обладает всем набором свойств целого агрегата как сложной системы. При этом до сих пор в значительной степени выделенно развивающееся направление 
On changes in concept...

исследований и теории агрегатирования трактора с сельскохозяйственной машиной/орудием (см. Рис. 1) (Ksenevich, Goberman and Goberman, 2003; Ksenevich, Gus'kov and Bocharov 1991) вместе с развитием теории и принципов объединения модулей в систему МТА являются основой развития современной теории таких агрегатов. Применительно к транспортным и транспортно-технологическим средствам повышенной проходимости такая попытка создания общей теории рабочих процессов и системного проектирования еще более тридцати лет назад сделана, например, д.т.н., проф. В.Н. Шалягиным (Shalyagin, 1986).

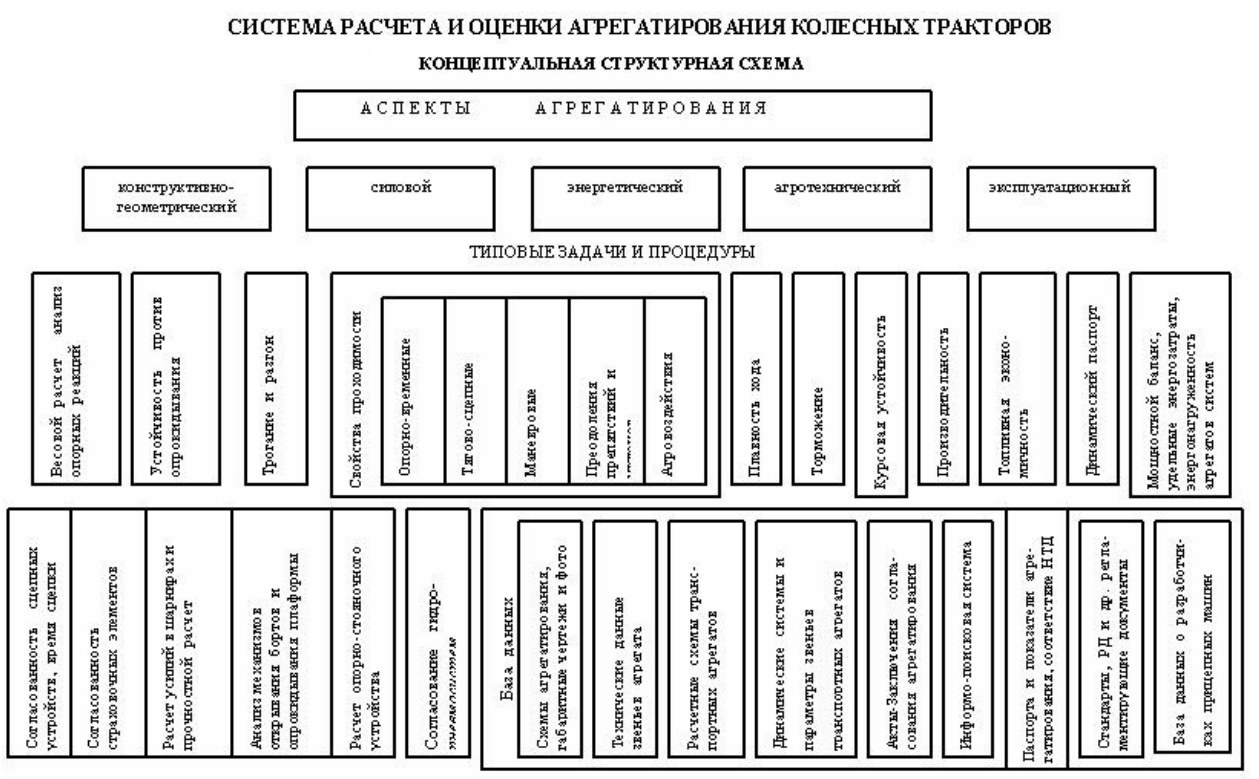

Рисунок 1. Система расчета и оценки агрегатирования колесных тракторов.

Представляет определенную проблему прогнозирование процессов обусловленной смены конструктивных концепций МТА в связи с развитием влияющих аспектов, изза их многочисленности и неочевидности тенденций изменения скоростей с течением календарного времени. Это касается в меньшей степени краткосрочных прогнозов на 5 лет, однако снижает надежность как среднесрочных, так и долгосрочных прогнозов. Пример, известный от 1990 года, графической иллюстрации изменения структуры потребления энергоносителей с прогнозной экстраполяцией на период до 2100 года показан на рисунке 2. Из рисунка, в частности, видна резко возрастающая роль водорода, полученного в биотехнологиях, путем электролиза воды и т.П., и его преобладание к 2100 году, хотя пока доля водорода в газовых энергоносителях незначительна. Это говорит о возможности отклонения прогноза от действительности. Однако, надежные среднесрочные прогнозы крайне необходимы для практики планирования, например НИОКР. 
Georgij Tajanowskij, Wojciech Tanaś, Mariusz Szymanek

Каждый прогноз отражает связь прошлого, настоящего и будущего. Надежный прогноз становится фактом. Конструктор чаще всего выполняет прогнозы: а)технологический прогноз применения данной техники; б) общих конструктивных компоновочных решений; в) прогноз развития параметров данного вида техники, принципа функционирования подсистем и т.п.

Для выполнения прогноза разработаны многочисленные методы прогнозирования: экстраполяции; экспертных оценок; методы моделирования: сценария, исторической хронологии и т.д.

Метод экстраполяции наиболее прозрачен и сводится к отысканию функции зависимости некоторых факторов (параметров техники) от времени на основе эмпирических данных за предысторию изучаемого процесса и к определению по этой зависимости значения оцениваемых факторов в будущие моменты времени.

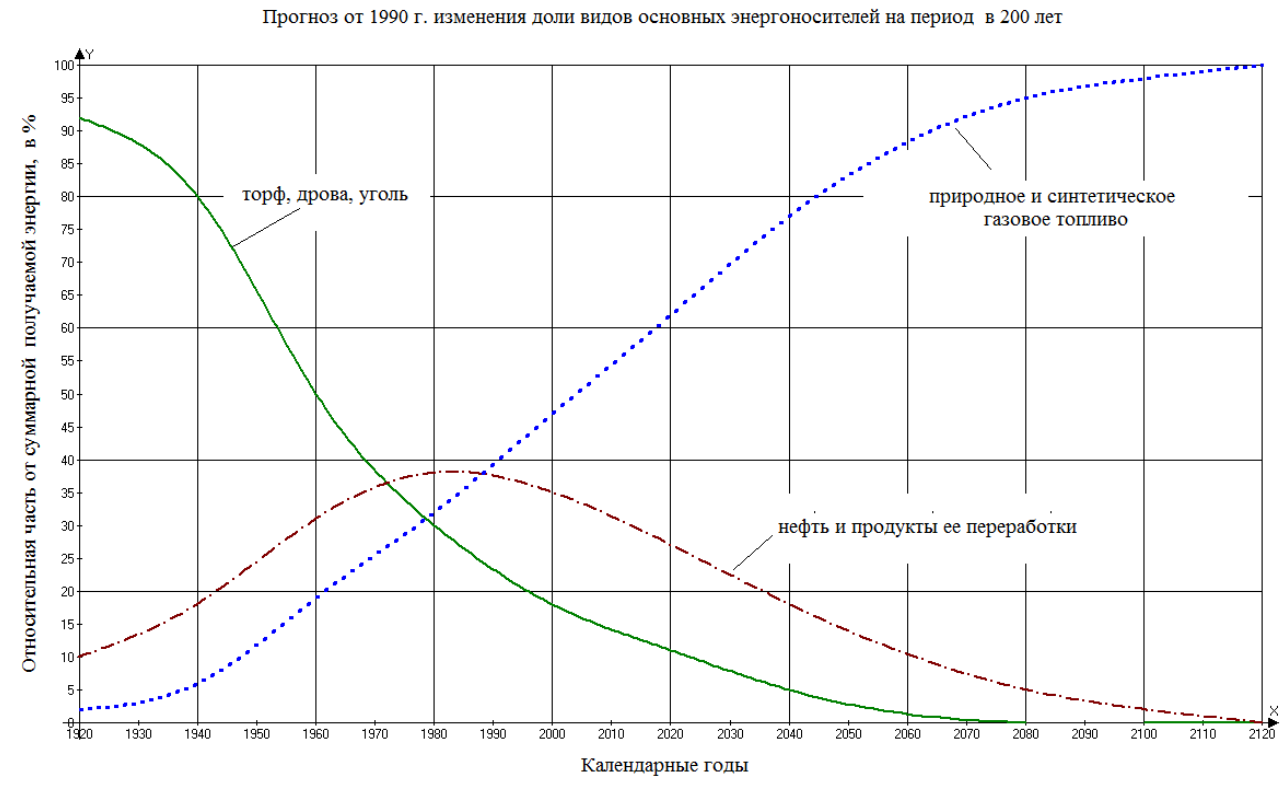

Рисунок 2. Вариант прогноза изменения использования энергоносителей.

Надежность прогноза методом экстраполяции зависит от достаточности исходных данных и правильного выбора соотношений интервала экстраполяции к интервалу ретроспекции. Обычно применяют это соотношение, равным 1/3. Наиболее простым математическим аппаратом для выполнения прогноза методом экстраполяции служит математический метод наименьших квадратов.

Метод экспертной оценки, по сути, состоит в том, что собирается коллектив специалистов-экспертов в данной области техники, которые по рациональной методике определяют превалирующую оценку коллектива экспертов о тенденции изменения во времени данного вида техники. В техническое задание на разработку изделия часто вносят как раз данные на основе результатов экспертной оценки. 
On changes in concept...

Надежный прогноз процессов замены старой техники техникой новых прогрессивных концепций особенно важен для разработчиков новой техники. Такие субституционные процессы подчиняются S-образным кривым, которые наиболее полно описываются формулой Перла (Kunilova, Antonenko and Karaulova, 2011).

Пусть, при оценке закономерностей упомянутых процессов, в качестве прогнозируемого фактора выбран объем выполняемых работ моделями разных конструктивных концепций техники одного назначения. При собранных данных по годам об объемах выполняемой работы находящимися в эксплуатации машинами каждой из концепций, типовое их графическое представление имеет вид, показанный на рисунке 3.

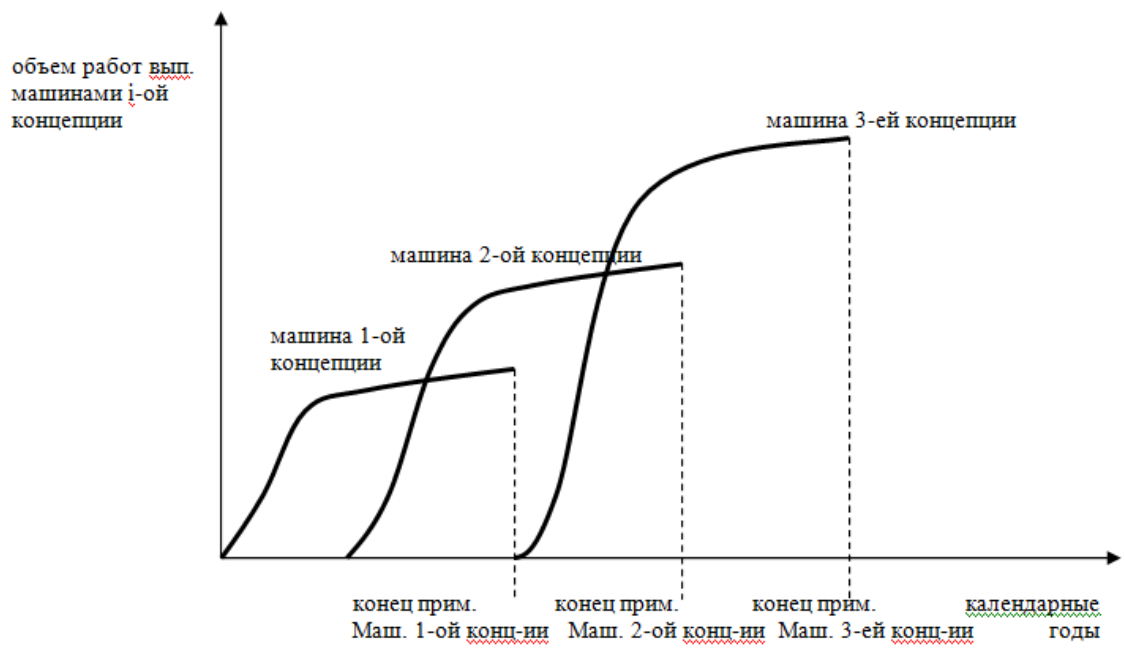

Рисунок 3. Характер S-образных кривых объемов выполненных работ машинами различных конщепџий и одного назначения.

График наглядно показывает, по календарным годам, моменты смены доминирующей на практике машины одной концепции на машину другой более прогрессивной концепции. Вывод для проектировщика состоит в том, что ему целесообразно разрабатывать улучшенную машину, аналогичную той концепции, которая либо доминирует в настоящее время (знак кривизны S-образной кривой не менялся, а объем выполняемых работ будет увеличиваться и превышать аналогичный для машин других концепций еще длительное время, достаточное для получения эффекта в народном хозяйстве от разрабатываемой машины). Либо необходимо создавать машину той концепции, которая, судя по прогнозу, зарождается (либо уже появились на рынке подобные машины конкурентов) и которая по техническому уровню будет превосходить своих предшественников или машины других альтернативных конструктивно-технологических концепций на момент выхода на рынок машины, которую только планируют к разработке. 
Georgij Tajanowskij, Wojciech Tanaś, Mariusz Szymanek

В случае существования машин, конкурирующих с задуманной, на выбранном сегменте рынка, при формулировании технического задания на разработку машины выполняют прогнозную оценку ее технического уровня и качества (ТУиК), а также строят так называемый радар конкурентоспособности, который наглядно показывает достоинства и недостатки задуманной машины, в сравнении с машинами конкурентов, либо со статистически определенными показателями так называемого "идеального" существующего товара (см. Рисунок 4).

Здесь под анализом понимается отыскание причинно-следственных связей между некоторыми факторами, на основании которых можно сделать вывод, дающий ответ на поставленный вопрос по теме и задачам проектирования:

a) анализ по пунктам Т3;

б) анализ конкурентоспособности по факторам, определяющим спрос, цену, объемы продаж, емкость рынка аналогов разрабатываемого изделия;

в) анализ различных аспектов данного вида изделия на основании изучения тенденции развития данного вида техники.

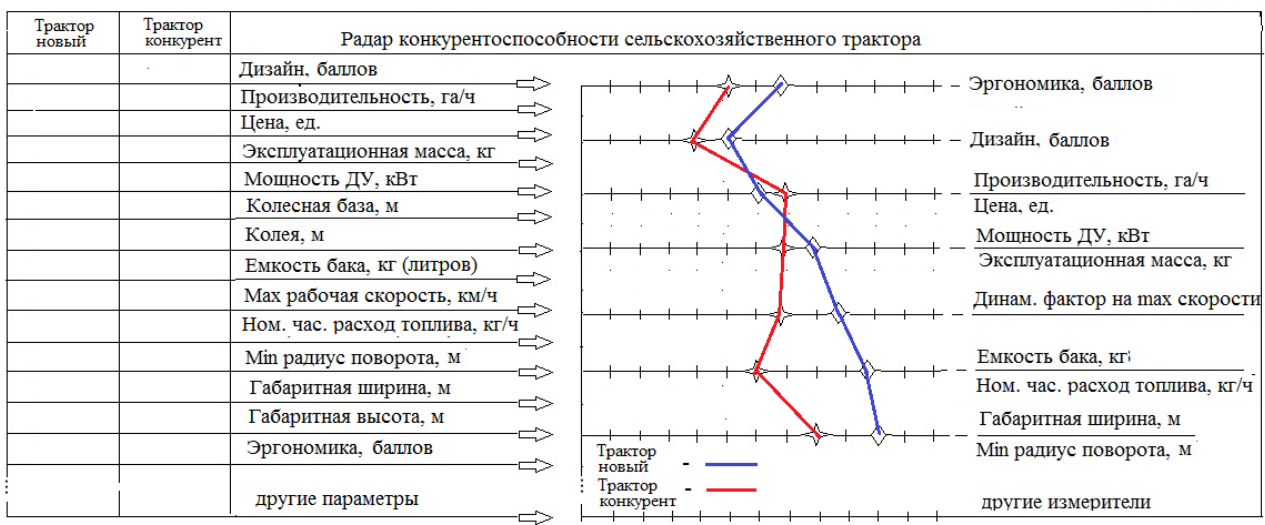

Рисунок 4. Пример радара конкурентоспособности анализируемых машин одного назначения

Алгоритм информационного обеспечения конструкторской подготовки разрабатываемого вида техники на стадии предпроектных исследований и разработки Т3 можно представить в виде варианта известной блок-схемы (Рисунок 5).

Для удобства интегральной оценки конкурентоспособности предполагаемой к разработке мобильной техники как раз и используют упомянутый радар конкурентоспособности (рисунок 4), который наглядно показывает преимущества и недостатки вашего варианта машины по отношению к наиболее близкому конкуренту или к обобщенному статистически объекту-идеальному товару для выбранного сегмента рынка данных машин.

Принятые по результатам анализа конкурентоспособности технико-экономических показателей (ТЭП) закладываются в Т3 на разработку мобильной машины. 
On changes in concept...

При выполнении процедур внешнего поисково-изыскательского проектирования и предпроектных исследований, необходимых для научно-обоснованного формулирования технического задания на разработку новой машины, используют, среди прочего, комплекс достаточно разработанных и многочисленных современных методов поиска нового технического решения, обладающего патенто- и конкурентоспособностью (Ksenevich, Gus'kov and Bocharov 1991), а также методологию оценки комплекса функциональных свойств с учетом действующих регламентов (ТР ТС 018/2011).

Анализ вариантов возможных структурно-компонентных схем общей компоновки разрабатываемого перспективного трактора удобно выполнять на основе комбинационной матрицы структур по алгоритмам метода морфологического вариантного анализа, либо любого продуктивного другого.

Исследование компоновок нового трактора на среднесрочную перспективу, с учетом имеющихся прогнозов развития агрегатируемых с тракторами машин и орудий и с учетом с.-х. технологий, выполняется путем анализа всего спектра свойств рассматриваемых вариантов и их сравнения между собой в рамках автоматизированного программного комплекса.

Суть обобщенного алгоритма предпроектного анализа свойств мобильной машины в том, чтобы обеспечить выполнение любой из проектных процедур, входящих в ее структуру и любой проектной операции - задачи, любое число раз.

Выполненное информационно-патентное исследование тенденций в изменении общей компоновки с.-х. тракторов ближайшего будущего показало, что реально происходит смена тягово-энергетической концепции дизельного трактора, управляемого водителем вручную, на мобильно-энергетическую концепцию электроприводного трактора с мехатронным управлением всеми функциональными подсистемами и возможностью автоматического или удаленного управления вождением с помощью подсистем точного позиционирования. При этом анализ опубликованных в печати и выставленных на презентациях концептов тракторов будущего обнаруживает определенную корреляцию их экстерьера и компоновочной схемы с выбором новых силовых установок, рассмотренных ранее, для таких машин. Приведем в качестве примера несколько раскрытых для технического сообщества вариантов концептов будущих тракторов с возможностью беспилотного управления от известных фирм (см. рисунки 6-11).

Дизайнерами Минского тракторного завода (Беларусь) создан модульный супертрактор трансформер, схема общей компоновки которого показана на рисунке 6 , а фото - в источнике (V Minske prezentovali futuristicheskiy traktor MTZ). Выполненные изыскания дизайна трактора класса 3 с изменяемой пространственной структурой сложны тем, что при учете всех требований и ограничений к устройству и свойствам трактора согласно Техническому регламенту СНГ, стандартов и т.п. необходимо достичь максимального результата в решении двуединой задачи: обеспечить функциональностъ в рамках наилучшего дизайнерского облика трактора. Это представление об идеализации для будущего машины данного вида. Какова вероятность того, что такой проект будет когда-нибудь реализован массово, определить сложно, так как это касается и аксиологического прогноза будущих потребностей человека. Это концепт, вариант возможного будущего, однако этот 
Georgij Tajanowskij, Wojciech Tanaś, Mariusz Szymanek

образец изготовлен в металле и работает, так как отдельные модули машины уже отработаны на эксплуатирующихся тракторах.

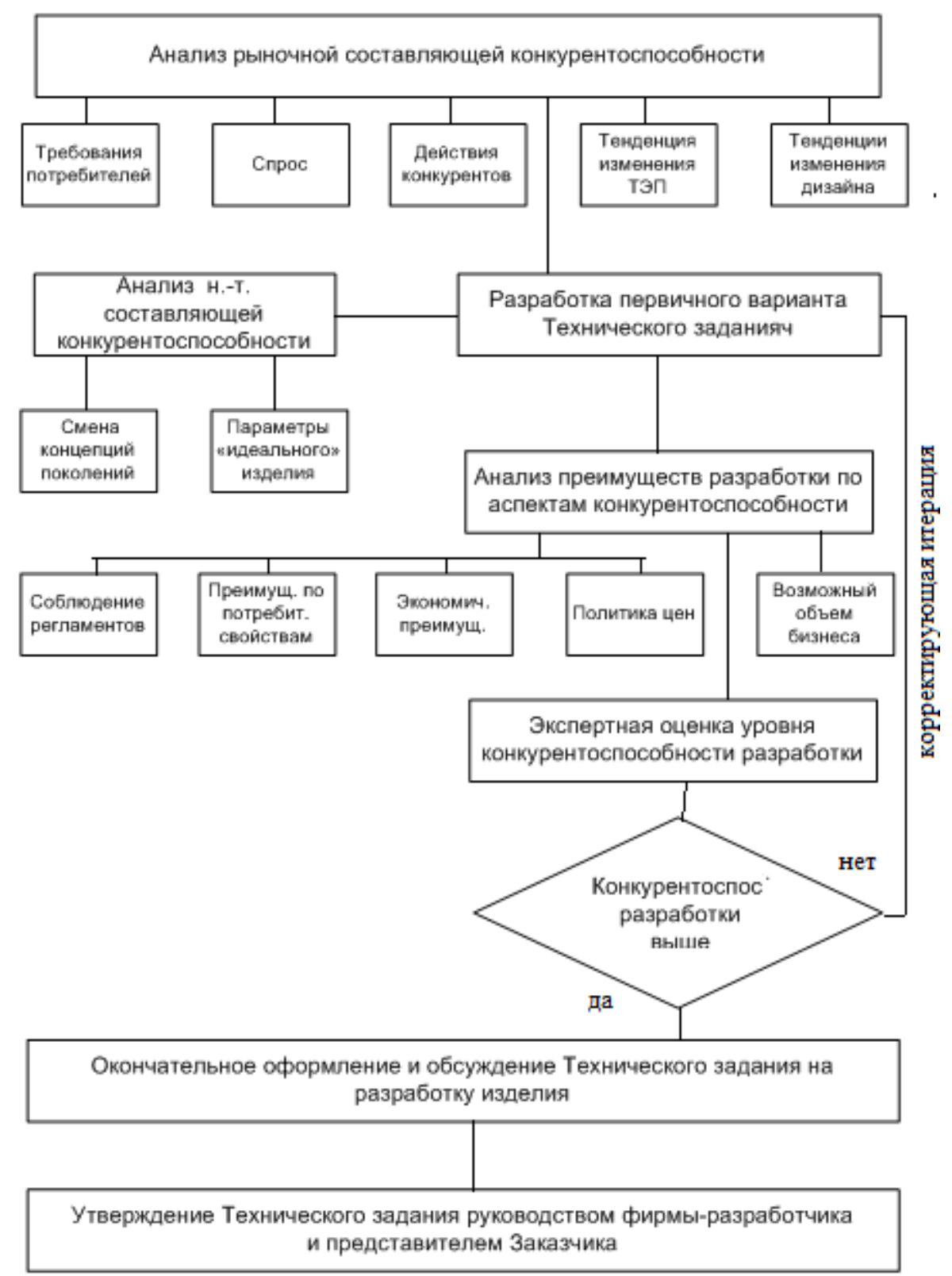

Рисунок 5. Схема алгоритма анализа трактора на конкурентоспособность 
On changes in concept...

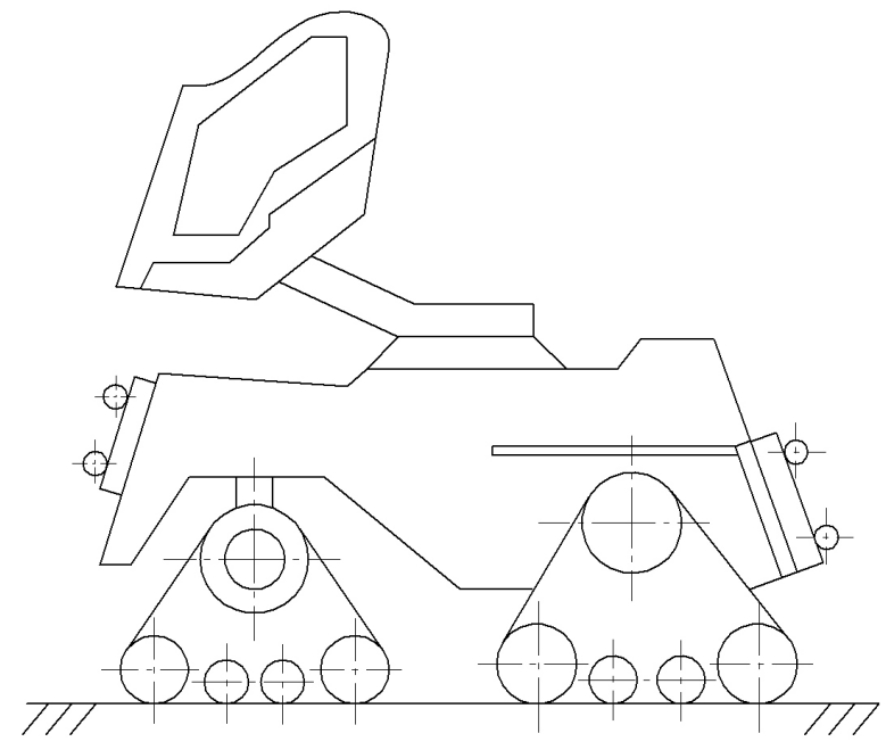

Рисунок 6. Концепт перспективного трактора с возможностью беспилотного управления

Ближайшая перспектива тракторостроения состоит в расширении модельного ряда электротракторов с обязательными кабинами, даже при оборудовании их системами автоматического вождения. Пример изменения дизайна трактора будущего фирмы CLAAS - одного из лауреатов международного конкурса iF Design Award за успешное сочетание хай-тек \& дизайн приведен в источнике (Tekhniku CLAAS nagradili za uspeshnoye sochetaniye khay-tek \& dizayn).

Габариты внешнего очертания трактора с электрической ДУ остаются почти прежние, только вместо дизеля под капотом размещен комплект электропривода. Для более далекой перспективы, при отсутствии кабины, реально расширение использования тракторов “беспилотников», что потребует также развития соответствующих разделов теории тракторного агрегата.

Далее (рисунки 7-11) приведены примеры эскизов подобных тракторов разных общих компоновок, которые находятся в том же фарватере поискового движения к новому. Практическая реализация этого направления уже началась, подтверждение тому в примерах трактора в источниках (V Minske prezentovali futuristicheskiy traktor MTZ; Traktor na steroidakh; Ekotekhnika; Tekhniku CLAAS nagradili za uspeshnoye sochetaniye khay-tek \& dizayn). А это уже признак начала формирования тенденции развития или тренда изменения концепции данного вида техники.

На рисунке 7 приведена компоновочная схема беспилотного трактора $4 \mathrm{x} 4 \mathrm{c}$ передними меньшими управляемыми колесами с использованием межосевого пространства на всю габаритную ширину с передними и задними сцепными устройствами, на рисунке 8 - полноприводный трактор с колесами одного размера и 
Georgij Tajanowskij, Wojciech Tanaś, Mariusz Szymanek

системой поворота типа «краб», оборудованный автоматом сцепки на трехточечном сцепном устройстве.
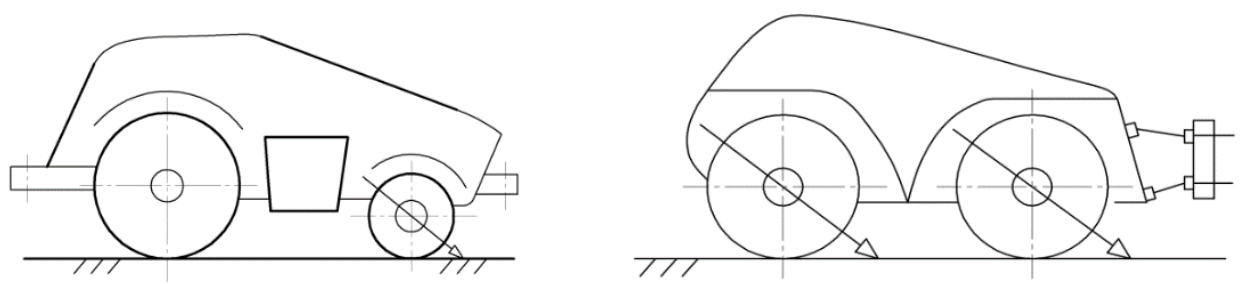

Рисунок 7. Схема беспилотного трактора $4 x 4$ Рисунок 8. полноприводный трактор с с передними и задними сцепными системой поворота типа «краб». устройствами.

На рисунке 9 приведена компоновочная схема беспилотного короткобазного трактора $4 \times 4$ с бортовой схемой поворота для работы на малых для разворота площадях, с возможностью агрегатирования широкого набора сменного рабочего оборудования с помощью универсальных электроуправляемых евроадаптеров. На рисунке 10 показана компоновочная схема мощного беспилотного полноприводного шарнирно-сочлененного трактора с развитыми площадками для размещения разнообразного технологического оборудования, а также с лифтовыми задним и передним сцепными устройствами, которые обеспечивают реализации передего, заднего, эшелонированного и других видов агрегатирования.

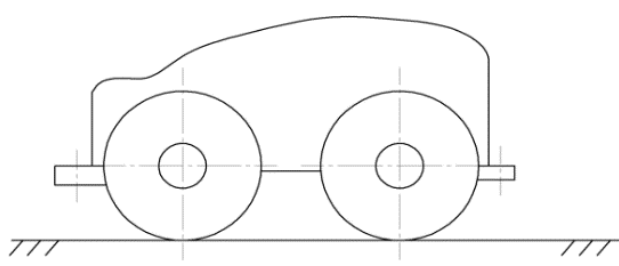

Рисунок 9. Схема беспилотного короткобазного трактора $4 \mathrm{x} 4$ с бортовой схемой поворота с возможностью оборудования с помощью универсальных электроуправляемых

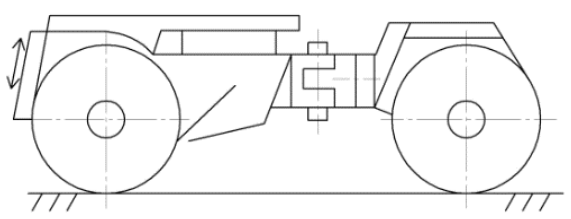

Рисунок 10. Схема мощного беспилотного полноприводного шарнирносочлененного трактора. евроадаптеров. 
On changes in concept...

Особенностью всех вариантов является применение систем электро- и гидроотбора мощности на привод активных рабочих органов агрегатируемого модульного быстросъемного технологического оборудования, которое также существенно видоизменяется конструктивно.

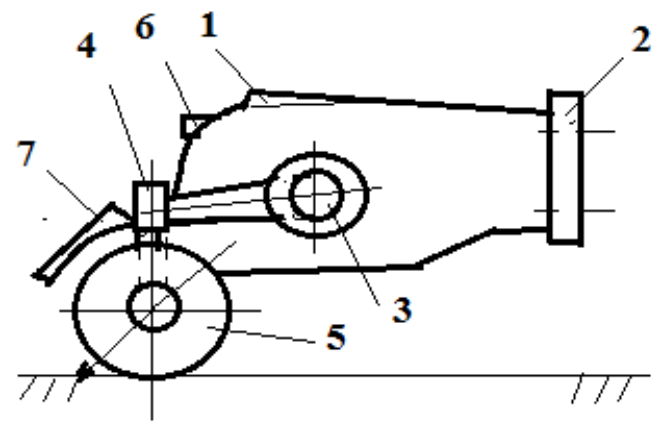

Рисунок 11. Симметричная конструкция трактора из двух тягово-приводных электромодулей. Обозначения: 1-корпус с электронакопителем; 2 - стыковочный узел; 3 - подпружиненный рукав колесной опоры; 4 - поворотный приводной шарнир; 5 - ведущее поворотное колесо; 6-ВОМ; 7 - панели солнечных батарей.

Симметричная конструкция трактора из двух тягово-приводных электромодулей (рисунок 11) позволяет различать движение по направлениям только при присоединении снизу и спереди какой-либо машины-орудия к такому трактору. Все поворотные колеса 5 оснащены электрическими моторами, их мощность распределяется индивидуально (Traktor na steroidakh). Трактор отличается большим диапазоном пространственной конструктивной эволюции и энергетической гибкостью. Электромоторы трактора могут получать часть необходимой энергии от солнечных батарей 7, установленных в верхней части корпуса 1 , и брызговиках, а основным источником являются электронакопители большой емкости.

Отдельное направление создания средств привода и перемещения с.-х. машин и орудий по полю состоит в развитии приводных несущих платформ с индивидуальным гидростатическим или электроприводом колес, либо резино-тросовых ведущих тележек, предназначенных для быстрого переагрегатирования, а также трансформируемых высококлиренсных мультимодульных тракторных шасси. Один из примеров подобных машин показан на рисунке 12 и в источнике (Kanadets izobrel bespilotnuyu zamenu traktora). 

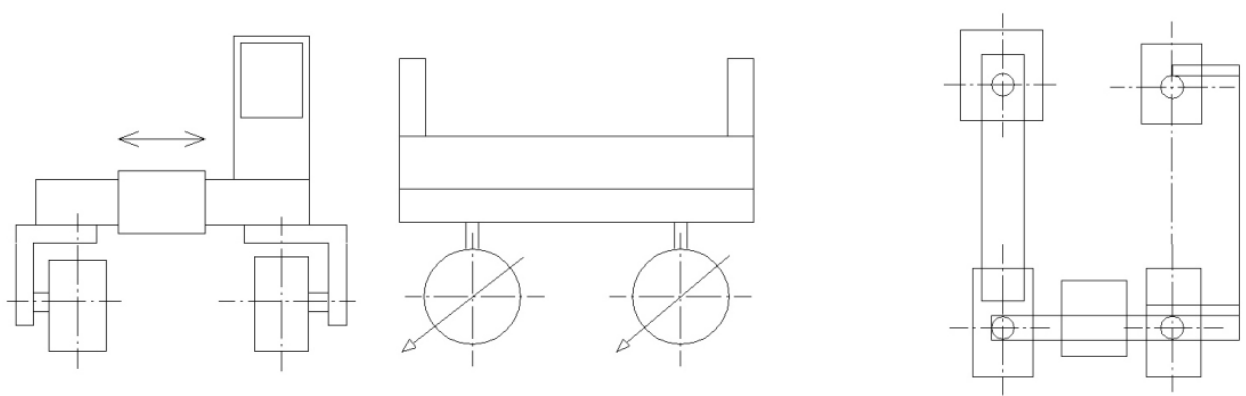

Рисунок 12. Схема приводных несущих платформ с индивидуальным гидростатическим или электроприводом колес

Существенное переуплотнение верхнего и подстилающего слоев возделываемых земель при многократных проходах ходовых систем тракторных агрегатов (Ksenevich, Skotnikov and Lyasko 1985), необходимость существенного снижения энергозатрат и повышения производительности труда в растениеводстве, а также экономических показателей, обусловливают, среди прочих причин, развитие работ в области создания широкозахватных портальных мобильных с.-х. технологических агрегатов с электроприводом, в том числе с использованием солнечной энергии.

Подобное направление развитие с.-х. МТА прогнозировала еще в 70 -х годах прошлого столетия научная школа проф. И.П.Ксеневича (Ksenevich, Goberman and Goberman 2003; Ksenevich, Gus'kov and Bocharov 1991). В некоторых префектурах Японии, где возможно выращивание двух урожаев риса в год, применяется технология с применением устройства в виде мостовой фермы, передвигающейся по направляющим на боковых сторонах бетонного чека, с которой осуществляется посадка проросших ростков рисового растения. Одним из примеров современного видения конструкции мобильного агрокомплекса для равнинных регионов с большой длительностью теплого периода, в чем-то подобным упомянутым в данном абзаце устройствам в виде мостовой фермы на поддерживающих ее и движущих беспилотных мини-тракторах, является мобильный агрокомплекс-робот (Ekotekhnika), который ориентирован на мультикультурность полей и может обеспечить возможность обрабатывать одновременно до восьми возделываемых культур на площади до нескольких тысяч гектар и повысить защиту растений от вредителей. Комплекс включает: мостовую ферму, беспилотные мини-тракторы, навесные манипуляторы для возделывания конкретных растений, солнечные панели и аккумуляторы электроэнергии. Он должен обеспечивать работу весь полевой сезон.

Однако часть из приведенных концептов развития с.-х. техники с тракторным беспилотным компонентом пока лишь обозначили нужду социума в новой более прогрессивной технике, но она еще не оформилась в финансово гарантированную им потребность. Однако изложенные факты как раз и свидетельствуют о зарождении и развитии очередного цикла смены концепций в сфере сельскохозяйственной тракторной техники. 
On changes in concept...

\section{Заключение}

Таким образом, в работе сформулированы выводы по анализу состояния разработок в тракторостроении, представлены общие методические положения предпроектного обоснования с.-х. трактора, необходимые для последующего выбора его рациональной общей компоновки и параметров по комплексу критериев качества, дизайнерского облика и конкурентоспособности, рассмотрены аспекты прогнозного представления о трансформации концепции общих компоновочных решений и необходимости развития теории перспективных машинных тракторных агрегатов, в связи с применением на тракторах новых перспективных двигательных установок и концептуально новых компоновочных решений сельскохозяйственной техники с тракторным компонентом.

\section{Литература}

Ekotekhnika. Internet-resurs. Rezhim dostupa: http://coverx.site/tag/kontsept.html

Kanadets izobrel bespilotnuyu zamenu traktora. Internet-resurs. Rezhim dostupa: http://agroportal.ua/ru/news/tekhnika/kanadets-izobrel-bespilotnuyu-alternativu-traktoru/

Katsygin, V.V. (1964). Osnovy teorii vybora optimal'nykh parametrov mobil'nykh s.- kh.mashin i orudiy. Voprosy s.-kh. mekhaniki. Minsk.

Kunilova, M.A., Antonenko, O.O., Karaulova, L.V. (2011). Statistika. V 2 ch. Chast' 2 - Sotsial'noekonomicheskaya statistika. Kirov: Izd-vo VyatGGU.

Ksenevich, I.P., Goberman, V.A., Goberman, L.A. (2003). Nazemnyye tyagovo-transportnyye sistemy. Entsiklopediya. V 3 tomakh. Mashinostroyeniye, ISBN: 5217031611.

Ksenevich, I.P., Gus'kov, V.V., Bocharov, N.F. (1991). Traktory. Proyektirovaniye, konstruirovaniye i raschet. Obshch. red. I.P. Ksenevicha. Moscow, Mashinostroyeniye.

Ksenevich, I.P., Skotnikov, V.A., Lyasko, M.I. (1985). Khodovaya sistema - pochva - urozhay. Moscow, Agropromizdat.

Shalyagin, V.N. (1986). Transportnyye i transportno-tekhnologicheskiye sredstva povyshennoy prokhodimosti. Moscow, Agropromizdat.

Tekhniku CLAAS nagradili za uspeshnoye sochetaniye khay-tek \& dizayn. Internet-resurs. Rezhim dostupa: https://vk.com/wall-94837837?own=1\&offset=80

TP TC 018/2011 - Tekhnicheskiy reglament Tamozhennogo soyuza "O bezopasnosti kolesnykh transportnykh sredstv".

Traktor na steroidakh. Zhurnal Naked Science № 41, (2018). Internet-resurs. Rezhim dostupa: https://naked-science.ru/article/concept/traktor-na-steroidah

V Minske prezentovali futuristicheskiy traktor MTZ. Internet-resurs. Rezhim dostupa: https://nn.by/?c=ar\&i=221453\&lang=ru 
Georgij Tajanowskij, Wojciech Tanaś, Mariusz Szymanek

\section{O ZMIANIE KONCEPCJI I OGÓLNEJ STRUKTURZE BUDOWY CIĄGNIKÓW ROLNICZYCH}

Streszczenie. Sformułowano wnioski z analizy stanu opracowań i tendencji w budowie ciągników. Rozpatrzono aspekty prognozy transformacji koncepcji, ogólnej struktury rozwiązań konstrukcyjnych $\mathrm{i}$ teorii perspektywicznych ciągnikowych agregatów maszynowych z nowymi układami napędowymi. Przedstawiono możliwe tendencje w przedprojektowym uzasadnieniu koncepcji budowy ciągników nowej generacji.

Słowa kluczowe: ciągnik, agregat ciągnikowy, struktura budowy, układy napędowe, moduły wyposażenia, koncepcja rozwoju 